DOI: http://doi.org/10.21698/simi.2018.ab38

\title{
NEW LC-MS METHOD FOR ACRYLAMIDE DETERMINATION IN ENVIRONMENTAL WATER SAMPLES
}

Florentina Laura Chiriac, Iuliana Paun, Florinela Pirvu, Liliana Cruceru, Luoana Florentina Pascu

National Research and Development Institute for Industrial Ecology - ECOIND, 71-73 Drumul Podu Dambovitei, district 6, 060652, Bucharest, laura.badea88@yahoo.com, Romania

Keywords: acrylamide, drinking water, SPE-LC-MS

\section{Introduction}

Acrylamide is a low molecular weight hydrophilic chemical and an intermediate used mostly in the production and synthesis of polyacrylamides and its copolymers.

In turn, polyacrylamide is used as additives for wastewater treatment and flocculant for raw water treatment. Acrylamide is the main impurity of polyacrylamide and it is released in the environment as residual monomer. Acrylamide has also been found in certain foods that have been cooked and processed at high temperatures. The International Agency for Research on Cancer classified acrylamide as a "probable carcinogen" to humans based on animal studies. World Health Organization (WHO) guideline value associated with a lifetime cancer risk is $0.5 \mu \mathrm{g} / \mathrm{L}$ in drinking water. Acrylamide has been regulated in European countries by the Drinking Water Directive which imposes a maximum admissible concentration of $0.1 \mu \mathrm{g} / \mathrm{L}$ for water intended for human consumption. For detection of very low concentration in environmental drinking water samples requires the development and validation of sensitive, robust and inexpensive analytical methods that can quantify acrylamide in drinking water matrices down to ppb levels. To avoid the derivatization procedure, required for GC determination, LC-MS/MS is a suitable method for determination of acrylamide due to its high selectivity and increased sensitivity. The objective of study was to develop a rapid and sensitive LC-MS/MS method for the detection and quantitation of acrylamide in environmental water samples.

\section{Materials and methods}

Standards of Acrylamide (AA) and isotopically labelled Acrylamide (13C3Acrylamide) which was used as internal standard were purchased from SigmaAldrich. Methanol and acetonitrile of HPLC-grade purity were acquired from Merck and Formic Acid of $99 \%$ purity from Supelco. SPE activated charcoal cartridges (Supelclean Coconut Charcoal - $2 \mathrm{~g}, 6 \mathrm{~mL}$ ) were acquired also from Supelco (Bellefonte, PA, USA). Analyses were performed using an Agilent 1260 series LC system (Waldbronn, Germany) coupled with an Agilent 6410B triple-quadrupole mass spectrometer with electrospray ionization source (ESI).

\section{Results and conclusions}

In order to obtain a good separation and lowest possible quantitation limit (LOQ), all liquid chromatographic and mass spectrometric parameters (Collision energy, Fragmentor voltage, Capillary Voltage and Cell accelerator voltage.) were optimized. 


\section{INTERNATIONAL SYMPOSIUM "THE ENVIRONMENT AND THE INDUSTRY", SIMI 2018, BOOK OF ABSTRACTS}

These are necessary steps for determination of extremely low levels of acrylamide expected to occur in different water sample matrices $(\mathrm{ng} / \mathrm{L})$. The chromatographic column was a Synergi Fusion RP $(150 \times 2.0 \mathrm{~mm}, 4.0 \mu \mathrm{m})$ from Phenomenex, the stationary phase being a $\mathrm{C} 18$ chain modified with polar embedded amide groups. The acrylamide was eluted from the column under isocratic conditions with a mobile phase consisting of $0.1 \% \mathrm{HCOOH}$ in water and $\mathrm{MeOH}$ in the ratio 30:70 (v/v). Mobile phase flow rate of $0.2 \mathrm{~mL} / \mathrm{min}$ was used and separation temperature was kept at $45^{\circ} \mathrm{C}$. Optimized injection volume of $10 \mu \mathrm{L}$ was used with water/MeOH (1:1) as sample diluent. Under these conditions, acrylamide and its internal standard eluted from the column in less than 3 minutes. Method development for acrylamide detection implied optimization of all MS parameters in order to determine extremely low levels of acrylamide expected to occur in drinking water $(\mathrm{ng} / \mathrm{L})$. All detection parameters of the triple quadrupole MS detector were modified to obtain maximum sensitivity. Collision energy of $10 \mathrm{~V}$, fragmentor voltage of $80 \mathrm{~V}$, capillary voltage of $6000 \mathrm{~V}$ and $1 \mathrm{~V}$ for cell accelerator voltage were the final chosen values that generate maximum peak area. The electrospray ionization source parameters were also modified in a wide range to obtain highest ionization efficiency for the analytes in terms of peak area but also in terms of signal-to-noise ratio $(\mathrm{S} / \mathrm{N})$. The source parameters were identical for both analytes, acrylamide and internal standard respectively: drying gas temperature was $300^{\circ} \mathrm{C}$, drying gas flow was $6 \mathrm{~L} / \mathrm{min}$ and nebulizer pressure was 40 psi.

The optimization of the LC-MS analysis method was followed by optimization of the solid phase extraction parameters to allow concentration of acrylamide from drinking water samples at $\mathrm{ng} / \mathrm{L}$ level up to $\mu \mathrm{g} / \mathrm{L}$ level which represents the MS detection limit. Acrylamide was extracted from $250 \mathrm{~mL}$ water samples using activated charcoal SPE cartridges. This adsorbent is usually efficient for highly polar molecules such as acrylamide and ${ }^{13} \mathrm{C}_{3}$-acrylamide. Before extraction, $1 \mathrm{~mL}$ of ${ }^{13} \mathrm{C}_{3}$-AA $(100 \mu \mathrm{g} / \mathrm{L})$ was added as surrogate IS to each water sample. The samples were passed through the SPE cartridges. Before elution, the cartridges were dried for 30 minutes. Elution was done with $10 \mathrm{~mL}$ of methanol at a flow rate of $1 \mathrm{~mL} / \mathrm{min}$. Under a gentle nitrogen stream, the extracts were evaporated to dryness and re-dissolved with $1.0 \mathrm{~mL}$ of water/MeOH (1:1) and transferred into injection vials prior to LC-MS analysis.

To account for its performance, the developed SPE-LC-MS method was validated with respect to linearity, precision, accuracy and limit of quantitation. MS detector response was tested and proved linear in the range $1-200 \mu \mathrm{g} / \mathrm{L}$, generating high correlation coefficients $\left(\mathrm{R}^{2}>0.999\right)$. The method proved to be precise with $\mathrm{RSD} \%$ values of $7.3 \%$ for intra-day precision and $10.3 \%$ for inter-day precision. Analyte recovery was $98 \%$ due to surrogate internal standard correction. Overall method LOQs were situated below $2.0 \mathrm{ng} / \mathrm{L}$.

The developed method is sensitive and accurate and allowed the detection of very low concentration of acrylamide in drinking water samples in less than 3 minutes.

\section{Acknowledgements}

The authors acknowledge the financial support offered by The National Research Program

"Nucleu" through Agreement no. 38N/2018, Project code PN 18050101. 